\title{
Innovative Organization's Components in Basic Education Institutions in Thailand
}

\author{
Aniruth Boonkua \\ King Mongkut's Institute of Technology Ladkrabang, Bangkok, Thailand, \\ $57603003 @$ kmitl.ac.th \\ Ampapan Tuntinakorngul \\ King Mongkut's Institute of Technology Ladkrabang, Bangkok, Thailand, \\ ampapan.tu@kmitl.ac.th \\ Pariyaporn Tungkunanan \\ King Mongkut's Institute of Technology Ladkrabang, Bangkok, Thailand, \\ pariya2511@gmail.com
}

This paper reports the innovative organization's components in basic education institutions in Thailand and the results of confirmatory factor analysis to validate those components. The data for analysis were collected from the samples of 84 school directors, 332 deputy school directors, and 84 heads of ICT department in schools of the Basic Education Commission, Ministry of Education in Thailand for the academic year of 2018, using stratified randomized technique. The tool for data collection was approved questionnaire with high content validity at 0.97 . The statistics used to analyse the data included means (M), standard deviation (S.D.), and Confirmatory Factor Analysis (CFA). The results revealed that (1) there were eight components and the highest level of the opinions of its importance was on the components of information and communications technology (ICT) management at 4.67(M) and S.D. at 0.31, and (2) there was a significant resemblance between the theory and the empirical data examined by a confirmatory factor analysis $\left(\chi^{2}=\right.$ $0.13, \chi 2 / \mathrm{df}=0.01, \mathrm{GFI}=0.99, \mathrm{AGFI}=0.97$, RMSEA $=0.03$ ).

Keywords: innovative organization, components of innovative organization, organization in basic education, basic education institutions, basic education in Thailand

\section{INTRODUCTION}

Innovation is one of the vital sources of growth and a key determinant of competitive advantage for success of organizations nowadays. Achieving innovation involves the coordinated efforts of many different players and the integration of activities across

Citation: Boonkua, A., Tuntinakorngul, A., \& Tungkunanan, P. (2020). Innovative Organization's Components in Basic Education Institutions in Thailand. International Journal of Instruction, 13(3), 31-42. https://doi.org/10.29333/iji.2020.1333a 
specialist functions, knowledge domains and contexts of application in the organizations (Van de Ven, Polley, Garud \& Venkataraman, 1999). The ability of such the organizations to innovate is a pre-condition for the successful utilization of inventive resources and new technologies. In the same way, the starter of new technology often presents complex opportunities and challenges for organizations, leading to changes in managerial practices and the emergence of new organizational forms. Organizational and technological innovations then are intertwined (Alice, 2004). Therefore; the emerging type of organization, so called innovative organization is introduced as it embraces innovation into every single unit of itself (Merx, Mireille, \& Wim, 2005). This also leads to supporting the innovation of personnel within the organization which in turn will create the capability of organization's competition in long-term (Vrakking ,1990).

In the education sector, the innovative organization can be considered a new alternative for organizational development which seeks to use innovation to drive management so that the educational organization can develop the whole system to respond well with the massive changes in the society. It is likely that the success of the educational organization and survival in such a fast-changing world depends on being creative, discovering new things and innovation (Adams, Bessant \& Phelps, 2006; Caldwell, F. \& O'Reilly, 2003).

There have been some studies showing that educational institutions have applied the concepts of innovative organizations at a certain level (Chen, Hsiao, Chang, Shen \& Chou, 2010). The studies of Papadakis and his colleagues (2016,2017); Sun, Wang \& Wang, (2018); Kong (2019) and Gong (2018), which focused on the use of technology as a tool for engaging students and teachers in teaching and learning were one case to show the relation of technology utilization as one main component for being an innovative organization. In addition, the other group of research emphasized on the management component. Chen et al., (2010). pointed out that innovative organization consist of innovative leadership; vision; innovative management; culture of innovation; media and instructional model and application for resource management. Seyed (2013) indicated that innovative organization consist of strategic and vision, organization structure, culture and working environment.; sharing and learning with ICT. Loaiza \& Abarca (2017), who conducted a research study on the determination of the innovation capability of the University of Ecuador, found that after applying MIES (The Innovation Model of Higher Education), the model could be used to explain the driving force in manufacturing innovation through MIES factors resulting in the ability to achieve innovation and create information useful for instructors at the university including corporate executives. In addition, it was found that it helped to make significant changes for educational development. Executives had innovation as a management model, instructors could innovate in new ways for teaching and learning, and students had innovative skills (Sitthisomjin, Somprach, \& Phuseeorn, 2018).

Moreover, some studies tried to figure out what the components of innovative organization could be. Christiansen (2000) found 8 components; vision and strategic; the competence Management system; goal; organization structure; technology 
information and communication management; decision method; incentive and personnel management system. Tidd, Bessant \& Pavitt (2001), presented 10 components consisting of shared vision; leadership and the will to innovate; appropriate organization structure; key individual; stretching training and development; high involvement in innovation; effective team working; creative climate; external focus; extensive communication and the learning organization. Von Stamm (2008) found 5 components; strategy and vision; leadership style; process; culture and physical environment.

Although much work has been done to find out the components of innovative organization, those works focused mainly on business sectors (Christiansen, 2000; Tidd, Bessant \& Pavitt, 2001; Von Stamm, 2008). Few works conducted on educational organization (Sitthisomjin, Somprach \& Phuseeorn, 2018). However, the study on the components of innovative organizations in basic education in Thailand has not been conducted yet. While the national education policy of the Office of the Education Council of Thailand is attempting to get all schools to become innovative organizations, there is not enough information provided on what the main components of innovative organization in basic education institutions in Thailand are (Office of the Education Council Ministry of Education, 2017). Therefore, the objectives of this study were to study the innovative organization's components in basic education institutions in Thailand and to do confirmatory factor analysis to validate the innovative organization's components in basic education institutions in Thailand. Based on the previous studies on innovative organization, the conceptual framework of this study consists of Cristiansen (2000), Tidd, Bessant \& Pavitt (2001), Von Stamm (2008), Wichitchanya, Durongwatana \& Vadhanasindhu (2012), Seyed (2013), Akin (2016), Van Lancker, Mondelaers, Wauters, \& Van (2016), Akpan (2016), Guimaraes \& Paranjape (2017) and Fernandes, Vasconcelos \& Dobelin (2018).

\section{METHOD}

\section{Population and Samples}

The population for the study was the total number of 335 school directors, 1,012 deputy school directors and 335 heads of ICT department in schools of Basic Education Commission. The samples included 84 school directors, 332 deputy school directors, and 84 heads of ICT department in schools under the Office of the Basic Education Commission. The sample size was determined following the methods by Hair et al., (2010) which stated that in analysing the components, researchers commonly use a sample size from $5-20$ times larger than the number of observed variables. In this present study, there are 20 observed variables, thus, allowing a total sample size ranging from $105-420$. Therefore, a sample of 500 participants was set by the researchers using stratified random sampling.

\section{Variables}

The variables were synthesized from the conceptual framework. After the synthesis of the 8 components of innovative organization using content analysis, these components were statistically analysed with CFA. These components consisted of: 1) strategic management; 2) organizational structure; 3 ) organizational culture; 4) innovative leader; 
5) human resource development; 6) information communication technology management; 7) work climate creation; and 8) learning organization.

\section{Research Tools}

The questionnaire used in this study was designed and verified for its reliability at 0.97 . It consisted of 61 questions contributing in 8 components as follows: strategic management; organizational structure; organizational culture; innovative leader; human resource development; information communication technology management; work climate creation; and 8) learning organization.

\section{Data Collection}

The data were collected using the questionnaire distributed to the participants who were directors, deputy directors, head of ICT departments. The 496 questionnaires were returned $(99.20 \%)$ and they were checked for their completion before the analysis process.

\section{Data Analysis}

1. The data were analysed with descriptive statistics; Mean (M) and Standard Deviation (S.D.) first to find out the sequence and importance of each component.

2. The confirmatory analysis was used to examine whether the empirical data from the first objective were congruent with the concept from the conceptual framework. Confirmatory Factor Analysis (CFA) performs its function as a multivariate analysis for testing concepts based on multiple measured indicators (Hair, Black, Babin, \& Anderson, 2010). Estimation methods in CFA include a maximum likelihood factor that determines the optimal value of the factor loading. A valid indicator can be used as convergence if the loading value on standard regression weight is higher than 0.5 or $\mathrm{p}<\alpha=.05$, the chi-squared $\left(\chi^{2}\right)$ value is small, the significance probability is higher than .05 (p>.05), and RMSEA is lower than 0.05 (Tabachnick \& Fidell, 2012). This method consisted of 4 phrases as follows. In the first phase, the Kaiser-Meyer-Olkin (KMO) test was utilized to find the suitability of the data (Jöreskog \& Sörbom, 1999). Then the second phase applied Bartlett's Test of Sphericity to measure the sampling adequacy. The third phase, Pearson's Correlation Coefficients was tested to find out the relationship between each pair of observed variables. In the final phase, Confirmatory Factor Analysis (CFA) was examined to check the validity of the model by LISREL 8.72. This analysed the fit of a model and its respective parameter estimates.

\section{FINDINGS}

The result of the opinions of the school directors, deputy school directors and heads of ICT's departments. 
Table 1

General Information of Participants

\begin{tabular}{lll}
\hline General information of participants & Number & Percentage \\
\hline Type of school & 251 & 50.60 \\
Government school & 245 & 49.40 \\
Private school & & \\
\hline Position & 83 & 16.73 \\
School directors & 331 & 66.73 \\
Deputy school directors & 82 & 16.54 \\
Heads of ICT departments & & \\
\hline
\end{tabular}

From table 1, the participants in this study consisted of 331 deputy school directors $(67.0 \%), 83$ school directors $(17.0 \%), 82$ heads of ICT departments $(16.0 \%)$. They came from 2 types of schools, 251 from government schools (51.0\%), and 245 from private schools $(49.0 \%)$.

Table 2

The Opinions of the School Directors, Deputy School Directors and Heads of ICT's Departments

\begin{tabular}{llll}
\hline Components & Mean & Std. Deviation & Meaning of results \\
\hline strategic management & 4.60 & 0.34 & Highest \\
\hline organizational structure & 4.40 & 0.35 & Highest \\
\hline organizational culture & 4.36 & 0.29 & Highest \\
\hline innovative leader & 4.57 & 0.40 & Highest \\
\hline human resource development & 4.53 & 0.31 & Highest \\
\hline $\begin{array}{l}\text { information communication technology } \\
\text { management }\end{array}$ & 4.67 & 0.31 & Highest \\
\hline work climate creation & 4.54 & 0.30 & Highest \\
\hline learning organization & 4.56 & 0.28 & Highest \\
\hline
\end{tabular}

From the table 2, it was found that the opinions about the innovative organization components of basic education institutions in Thailand in information communication technology management had the highest level of its importance while organization culture was considered the least important.

The results of the validation of the innovative organization's components by CFA.

The results of the validation of the innovative organization's components were shown in the Table $3-5$ and Figure 1 as follows.

Table 3

Kaiser-Meyer-Olkin (KMO) Measure of Sampling Adequacy and Bartlett's Test of Sphericity

\begin{tabular}{llll}
\hline Variables & KMO & Bartlett's Test of Sphericity & Sig. \\
\hline $\begin{array}{l}\text { The components of the innovative } \\
\text { organization of basic education }\end{array}$ & 0.91 & 2446.48 & 0.00 \\
institutions in Thailand. & & & \\
\hline
\end{tabular}


Table 3 presented the results of a preliminary agreement for confirmatory analysis of the innovative organization components of basic schools using tests to determine the suitability of the data (Kaiser-Mayer-Olkin: KMO) and to examine the relationship between questions. If there is a high relationship or significant relationship, it can be analysed for the component. The research found the KMO was 0.91 (marvelous/ excellent). In addition, the correlation between questions was tested by Bartlett's Test of Sphericity and the data correlated significantly (Hutcheson \& Sofroniou, 1999). The analysis confirmed that Bartlett's Test of Sphericity was equal to 2446.48 and was significant $(\mathrm{p}-$ Value $=0.00)$. Therefore, it could be confirmed that the test results were in accordance with the preliminary agreement.

Table 4

Significant Results of the Reported Variables and Their Interrelationship.

\begin{tabular}{|c|c|c|c|c|c|c|c|c|}
\hline Variables & SM & OS & $\mathrm{OC}$ & IL & $\mathrm{HR}$ & IT & WC & $\mathrm{OL}$ \\
\hline strategic management (SM) & 1.000 & & & & & & & \\
\hline organizational structure (OS) & $.560 * *$ & 1.000 & & & & & & \\
\hline organizational culture (OC) & $.666 * *$ & $.486 * *$ & 1.000 & & & & & \\
\hline innovative leader (IL) & $.678 * *$ & $.511^{* *}$ & $.681 * *$ & 1.000 & & & & \\
\hline $\begin{array}{l}\text { human resource development } \\
\text { (HR) }\end{array}$ & $.665^{* *}$ & $.572 * *$ & $.536 * *$ & $.505 * *$ & & & & \\
\hline $\begin{array}{l}\text { information communication } \\
\text { technology management (IT) }\end{array}$ & $.622 * *$ & $.473 * *$ & $.614 * *$ & $.556^{* *}$ & $.631 * *$ & 1.000 & & \\
\hline work climate creation (WC) & $.683 * *$ & $.455 * *$ & $.491 * *$ & $.430 * *$ & $.698 * *$ & $.602 * *$ & 1.000 & \\
\hline organizational learning (OL) & $.612 * *$ & $.498 * *$ & $.461 * *$ & $.539 * *$ & $.670 * *$ & $.575 * *$ & $.598 * *$ & 1.000 \\
\hline
\end{tabular}

From the table 4, the relationship test of the variables showed that the studied variables were correlated with statistical significance at the level of 0.01 . The highest correlated variables were work climate creation (WC) and human resource development (HR) with the relationship value of 0.698 , followed by work climate creation (WC) and strategic management $(\mathrm{SM})$ with the relationship value of 0.683 . However, the variables with relationship value of 0.430 were considered the least correlated which were 'work climate creation (WC) and innovative leader (IL).

Table 5

CFA. Results for the Components of Innovative Organization in Basic Education Institutions in Thailand.

\begin{tabular}{lcccl}
\hline Goodness-of-fit index & Criteria & Statistics & Outcome & Reference \\
\hline$\chi^{2}$ & $\mathrm{p}>0.05$ & 0.13 & Passed & Byrne (2001) \\
\hline$\chi^{2}$ /df & $\leq 2.00$ & & Passed & Hair et al. (2010) \\
\hline GFI & $>0.90$ & 0.99 & Passed & Byrne (2001) \\
\hline AGFI & $\geq 0.90$ & 0.97 & Passed & Schumacker \& Lomax (2010) \\
\hline RMSEA & $<0.08$ & 0.03 & Passed & Schumacker \& Lomax (2010) \\
\hline
\end{tabular}




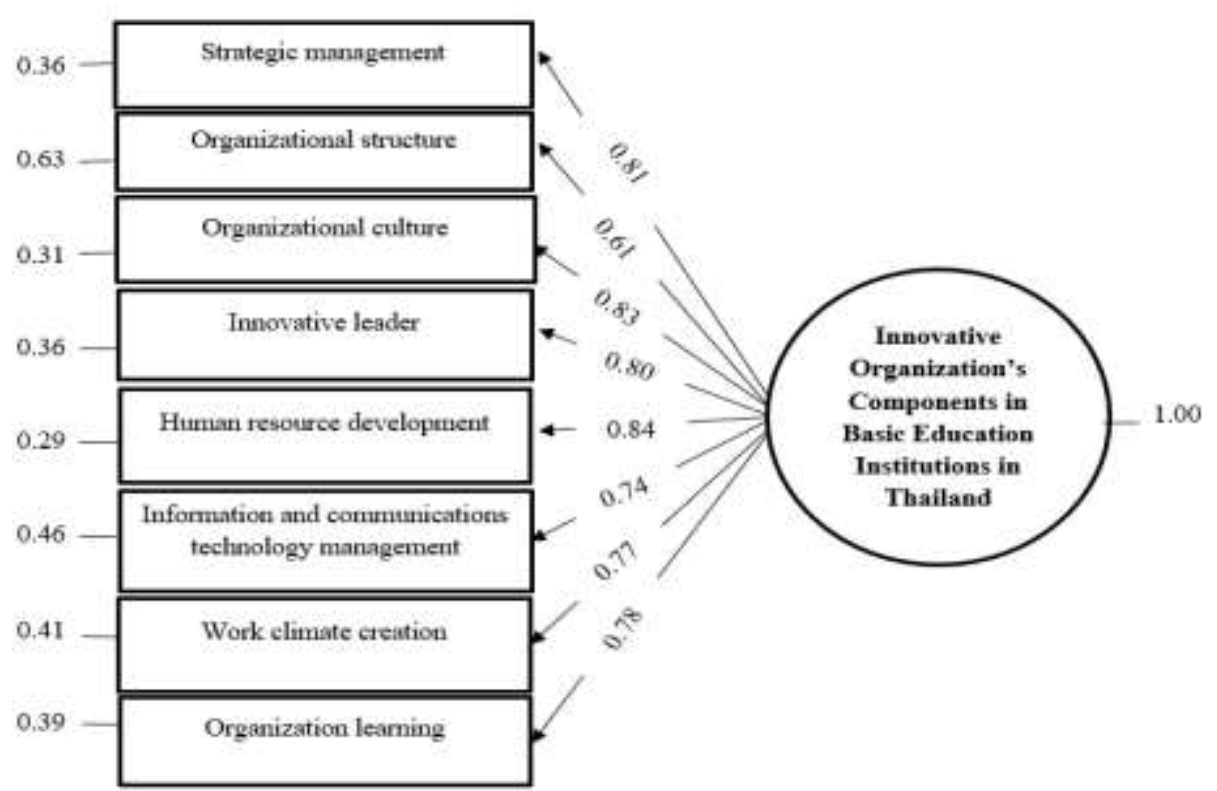

Figure 1

Results of the Confirmatory Factor Model Analysis of Innovative Organization in Basic Education Institutions in Thailand

From table 5 and Figure 1, the statistical analysis revealed that, at the 0.05 significant level, the chi-square result was 13.78 and the p-value was 0.13 . The goodness of fit index (GFI) was 0.99, while the adjusted goodness of fit index (AGFI) was calculated as 0.97. Both GFI and AGFI confirmed that this was a good fitting model as they both exceeded 0.90. Then the root means the square error of approximation (RMSEA) was 0.033. It can be confirmed that there was consistency across the defined criteria with a value of less than 0.08 . Overall, the results of the confirmed component analysis were consistent with the empirical data.

When considering the weight value of all components, each factor loading showed greater value than 0.30 ranging from $0.61-0.84$. The first four loading factors values in range of $0.80-0.84$ were human resource development $(0.84)$, organizational culture (0.83), strategic management (0.81) and innovative leader $(0.80)$. It was found that the analysis results were confirmed and the weights of all the variables were statistically significant at the 0.05 level as shown in Fig. 1.

\section{DISCUSSION}

The results from the first objective showed that all components were considered essential for innovative organization in basic education institutions in Thailand. Nevertheless, ICT management was prioritized as the most crucial component. this was acceptable as Pei (2015) study pointed out that ICT played an enormous role as the 
foundation of innovative organization. It is worth to say that IT or information communication technology management (IT) can be a key factor of an innovative organization since ICT involves a combination of technologies for collecting, storing, processing, communicating and distributing information related to management as well as teaching and learning processes. More importantly, information and communications technology can promote sharing of educational resources, deliver more educational resources to rural primary and middle schools (Loaiza, \& Abarca, 2017). In fact, basic education institutions in Thailand are in the process of developing the ability to manage information technology as a tool for directors for decision making and planning of educational innovation plan (Sitthisomjin, Somprach, \& Phuseeorn, 2018). Moreover, the analysis and interpretation of the data indicate that technology at the level of educational management may represent a valid solution for modern educational system (Gong, 2018) such as the use of new educational and technological innovation in forms of distance education or online learning platforms, Internet technology, providing students and teachers with access to electronic libraries; creating innovation for educational process and manage of school information system (Manea, 2015 ; Mykhailyshyn, Kondur, \& Serman, 2018). Therefore, to develop the quality of teaching and learning. Modern technology needs to be used as a tool to manage large data from the quality development planning system, to create a management development program, to use information for decision making together with the development of ICT skills of teachers and educational personnel in order to have access to information, and to organize information and using the information in teaching and learning management this must be supported by school administrators (Akpan, 2016).

From CFA method, it can validate the innovative organization's components in basic education institutions in Thailand. The results of this second objective were consistent with the results of some previous studies such as Akpan (2016), whose findings showed that the use of modern technological tools has greatly improved communication in schools. School directors should apply new tools from innovations to communicate with staff and students within and outside the school. In addition to the above, the important component of the innovative organization in basic education institutions in Thailand is that of human resource development. The findings showed that human resource management was the factor with the highest effect on an innovative organization in basic education institutions in Thailand, Therefore, educational institutions should develop teacher and personnel activities based on technology, develop programs from the development plan system, and provide training and performance assessment. In those developmental process, the development method depends on the environment, economic condition, corporate culture creation, promotion of learning and increase the opportunity for new skills to be developed (Wichitchanya, Durongwatana \& Vadhanasindhu, 2012). The component with the second highest effect was organizational culture. It conforms to the concepts of the characteristics of work culture to work values by aiming to encourage members of the organization to interact and support each other (Sitthisomjin, Somprach \& Phuseeorn, 2018). and having the organization's condition and workload appropriate for encouraging employees to be creative and supporting new ideas or ways of working (Szczepańska, 2014). Another important component which showed quite 
high effect in the experiment was organizational strategy. This was consistent with Li et al.'s study which found that determination of organizational strategy played a vital role and should state the long-term objectives and alternative strategies (Li, Bhutto, Nasiri, Shaikh, \& Samo, 2018). In addition, innovative organizations should have risk management plan since the innovative organizations often face high risks due to the need to produce more innovations (Guimaraes \& Paranjape, 2017). Innovation strategies must be clear and state what the organization needs and wants to be in the future (Von Stamm, 2008). After all, all components have been proven statistically that they were applicable components of innovative organization in basic education institutions in Thailand.

Since the National Education Policy states that schools in Thailand must change to become innovative organizations, the implications from this study could be that ministry of Education should provide guideline or framework as a strong foundation to create and develop the administration model of basic educational institutions. Moreover, the Office of the Basic Education Commission of Thailand can use the research results to formulate a strategic framework for the development of educational institutions.

\section{CONCLUSION}

To become quality basic education institutions in Thailand, this research has proven that there must be 8 compulsory components including: 1) strategic management; 2) organizational structure; 3) organizational culture; 4) innovative leader; 5) human resource development; 6) information and communications technology (ICT) management; 7) Work climate creation; and 8) Learning organization. Based on the results of the study, obviously, the most distinctive component is ICT Management as a key factor in developing an innovative organization. Nevertheless, the rest have been verified for their essence to be prevailing components as they supplement each other. Also, there was a significant resemblance between the theory and the empirical data examined by a confirmatory factor analysis. If educational institutions use innovation in personal development based on competency, the personnel can also enhance the innovation development capabilities of the organization. Finally, when institution management focuses on innovation throughout the organization, from communication in administration, teaching management or even exam management by using the process of learning exchange in innovation to develop the school management process, this will result in an organizational culture using technology as a base to develop and encourage endless research and innovation development.

\section{Suggestions}

Based on the findings, the following suggestions are offered to develop an innovative organization in basic education institutions in Thailand as follows. School directors, deputy school directors, and heads of ICT department support staff should be proficient in the use of technology in support of information communication and technology for school management. Teachers and educational personnel should be developed to have the knowledge and ability in using technology and to develop innovation for teaching and learning management. Further research, covering more government schools and 
private schools, should be conducted to confirm the findings of the current study and support its contribution towards the development of research data.

\section{REFERENCES}

Adams, R., Bessant, J., \& Phelps, R. (2006). Innovation management measurement: A review. International Journal of Management Review,8(1),21-47.

Akin, U. (2016). Innovation efforts in education and school administration: Views of Turkish school administrators. Eurasian Journal of Educational Research, 63,243- 260.

Akpan, C. (2016). Innovative practices in school administration. International Journal of Educational Administration Planning and Research, 6(8),45-53.

Alice Lam. (2004). Organizational innovation. London: School of Business and Management Brunel University.

Byrne, B. M. (2001). Structural equation modeling with AMOS, EQS, and LISREL: Comparative approaches to testing for the factorial validity of a measuring instrument. International journal of testing, 1(1),55-86.

Caldwell, D. F., \& C. A. O'Reilly. (2003). The determinants of team-based innovation in organizations: The role of social influence. Small Group Research, 34(4),97-517.

Chen, S. C., Hsiao, H. C., Chang, J. C., Shen, C. H., \& Chou, C. M. (2010). School organizational innovative indicators for technical universities and institutes. Contemporary Issues in Education Research,3(7), 43-50.

Christiansen, J. A. (2000). Building the innovative organization: Management systems that encourage innovation. Hampshire: Macmillan Press.

Fernandes Rodrigues Alves, M., Vasconcelos Ribeiro Galina, S., \& Dobelin, S. (2018). Literature on organizational innovation: past and future. Innovation \& Management Review, 15(1),2-19.

Gong, Y. (2018). Innovative English classroom teaching based on online computer technology in rural middle and primary schools. International Journal of Emerging Technologies in Learning (iJET),13(10),4-14.

Guimaraes, T., \& Paranjape, K. (2017). The effect of organization innovativeness on company innovation success. International Journal of the Academic Business World, 11(2),79-92.

Hair, J. F., Black, W. C., Babin, B. J., \& Anderson, R. E. (2010). Multivariate data analysis. Prentice Hall. New Jersey.

Hutcheson, G., \& Sofroniou, N. (1999). The multivariate social scientist: Introductory statistics using generalized linear models. Thousand Oaks, CA: Sage Publication.

Jöreskog, K. G., \& Sörbom, D. (1999). LISREL 8 user's reference guide. Lincolnwood, IL: Scientific Software International. 
Kong, J. (2019). Innovative applications mode of network learning space in exercise physiology based on ubiquitous learning. International Journal of Emerging Technologies in Learning, 14(4),113-126.

Li, W., Bhutto, T. A., Nasiri, A. R., Shaikh, H. A., \& Samo, F. A. (2018). Organizational innovation: The role of leadership and organizational culture. International Journal of Public Leadership, 14(1),33-47.

Loaiza, M., \& Abarca, P. A. (2017). Determination of the innovative capacity of Ecuadorian Universities. Journal of New Approaches in Educational Research (NAER Journal),6(1),57-63.

Manea, A. D. (2015). Innovation in the management of educational institutions. Procedia-Social and Behavioral Sciences, 209,310-315.

Merx-Chermin, Mireille., \& Wim J. Nijhof. (2005). Factors influencing knowledge creation and innovation in an organization. Journal of European Industrial Training, 29 (2), 135-147.

Mykhailyshyn, H., Kondur, O., \& Serman, L. (2018). Innovation of education and educational innovations in conditions of modern higher education institution. Journal of Vasyl Stefanyk Precarpathian National University,5(1),9-16.

Office of the Education Council Ministry of Education. (2017). Education in Thailand. Bangkok: Prigwan Graphic.

Papadakis, S. (2016). Creativity and innovation in European education. 10 years eTwinning. Past, present and the future. International Journal of Technology Enhanced Learning, 8(34), 279-296.

Papadakis, S., \& Kalogiannakis, M. (2017). Mobile educational applications for children. What educators and parents need to know? International Journal of Mobile Learning and Organization, (Special Issue on: Mobile Learning Applications and Strategies), 11(3),256-277.

Pei, L. I. U. (2015). An innovative exploration on primary and secondary school class management. Canadian Social Science,11(6),128-133.

Schumacker, R. E., \& Lomax, R. G. (2010). A beginner's guide to structural equation modeling (3rd ed.). New York, NY, US: Routledge/Taylor \& Francis Group.

Seyed, H. R. (2013). Management of organizational innovation. International Journal of Business and Social Science,4 (1),226-232.

Sitthisomjin, J., Somprach, K., \& Phuseeorn, S. (2018). The effects of innovation management on school performance of secondary schools in Thailand. Kasetsart Journal of Social Sciences,39,1-6.

Sun, H., Wang, X., \& Wang, X. (2018). Application of blockchain technology in online education. International Journal of Emerging Technologies in Learning (iJET), 13(10),252-259. 
Szczepańska-Woszczyna, K. (2014). The importance of organizational culture for innovation in the company. In Forum Scientiae Oeconomia, 2 (3),27-39.

Tabachnick, B.G. \& Fidell, L.S. (2012). Using multivariate statistics. Boston: Person Education.

Tidd, J., Bessant, J., \& Pavitt, K. (2001). Managing innovation integrating technological market and organization change. Chicester: John Wiley \& Sons.

Van de Ven, A., D. Polley, S. Garud and S. Venkataraman. (1999). the innovation journey. New York: Oxford University Press.

Van Lancker, J., Mondelaers, K., Wauters, E., \& Van Huylenbroeck, G. (2016). The organizational innovation system: A systemic framework for radical innovation at the organizational level. Technovation, 52,40-50.

Von Stamm, B. (2008). Managing innovation, design and creativity. John Wiley \& Sons.

Vrakking, W. J. (1990). The innovative organization. Long Range Plan, 23(2), 94-102.

Wichitchanya, W., Durongwatana, S. \& Vadhanasindhu, P., (2012). The components of the innovative organization: Evidence from Thailand. Review of Business \& Finance Case Studies, 3 (1),13-21. 